Journal of Social Sciences 6 (1): 47-49, 2010

ISSN 1549-3652

(C) 2010 Science Publications

\title{
The Development of Potential Problem Solving of Students, Mahasarakham University
}

\author{
${ }^{1}$ Amorn Suwannimitr, ${ }^{2}$ Choochart Deeromram and ${ }^{2}$ Suwadee Jundeekrayom \\ ${ }^{1}$ Department of Community Nursing, \\ ${ }^{2}$ Department of Psychiatric Nursing, \\ Faculty of Nursing, Mahasarakham University, Thailand
}

\begin{abstract}
Problem statement: The problem is a state of difficulty that needs to be resolved. It is involve in daily life of everyone including the students who study in University. Basically, they have to face with the physiological and psychological change; the significant problems also exactly affected to them. These situations led them to be the risk group in which they would have inappropriate behaviors. Consequently, the quality of life of the students, their families and society would impact eventually. Approach: To (1) describe the potential of problem solving of the students of Mahasarakham University, (2) compare the potential of problem solving between the group of students, (3) purpose the strategies to improve problem solving potential. This descriptive research using cluster random sampling, to define the sample, which consisted of 355 students, separated by 3 group. They were: (1) Human-Social Science, (2) Science and Technology and (3) Health Science. The research instrument was the problem solving inventory which comprised of three components; (1) problem solving confidence (2) approach-avoidance style and (3) personal control. Descriptive statistic and inferential statistic (t-test, F-test) was applied. Results: The majority of the subjects were female (77.2\%) the mean age of 18.66 and more than $55.8 \%$ were over 19 years old. Most of them were studied in the area of Human and Social Science $(69.3 \%)$. The problem solving potential level of these students in overall were in moderate level with the mean scores of 102.95. To divided by group, their mean score were: (1) the Human-Social Science group = 104.85 (2); the Health Science group $=94.86$ and (3) the Science and Technology $=105.32$. Most of students who able to solve the problem quite well were coping with the positive approach by did not avoiding the problem. In addition, they played attention with problem analysis, using emotional control and using the process of decision making. In contrast, the other group of students who unable to solve the problem, the research found that some of them were out of emotional control. They were avoidance and lack of self confident to solve the problem. It was not significantly different between gender. $(t=0.956, p>0.05)$, but it is significantly different between group. It shown that the Health Science group were able to solve the problem better than the Humanity-Social Science and Science and Technology groups, $(p=0.000)$. By the way, it was not significantly different between the Humanity-Social Science and Science and Technology groups $(\mathrm{p}=0.839)$. Conclusion: The findings suggested the strategies of problem solving potential development should be develop by covering these elements: (1) to develop the strengthening of mental and insight (2) to develop the learning system and (3) to develop leadership more than that it should develop the instructors role in teaching by using problem solving technique including with supportive system from the academic institute.
\end{abstract}

Key words: Problem solving, strategies for students

\section{INTRODUCTION}

Background and significance of research problem: The modern society and others factors are lead people in to the problem situations. The problem is a state of difficulty that needs to be resolved (WorldNet Search, 2009) or an issue or obstacle which makes it difficult to achieve a desired goal. One of the specific group that have to face with this situation is the teenager group. This situation involve in daily life of all person including with the students in University. Basically, the students have to cope with the physiological and psychological change, These factors led them to be the risk group. In which they would have inappropriate

Corresponding Author: Amorn Suwannimitr, Department of Community Nursing, Faculty of Nursing,

Mahasarakham University, Thailand 
behaviors, related with the environment, parents, friends, living conditions, education and many other factors. Teenagers face with many problems such as drug addicted and alcohol (Nies and Mc Even, 2001). Consequently of this situation, it effected to their quality of life. More than that its also impact to their families and society. Then it is necessary to find out the appropriate of the problem solving strategies.

Problem solving was defined as higher-order cognitive process, requires the modulation and control of more routine or fundamental skills. It occurs if an organism or an artificial intelligence system does not know how to proceed from a given state to a desired goal state. It is part of the larger problem process that includes problem finding and problem shaping (Rappaport and Seidman, 2000; Lazarus and Folkman, 1984; University of South Australia, 2009), or solving a problem was define in the sense of making it go away, then the problem no longer exists. This indeed is one kind of solution, but it is not the only kind (Harris, 1998).

Mahasarakham University is locate in the northeast of Thailand, which are increasing of the number of students every year. Most of them were teenager, some of them have to face with the problem and they can using a positively approach, in the other hands, we found that some of them could not solving the problem and using the negative approach. This research was describe the student's potential of problem solving and to purpose the strategies to improve student's problem solving potential.

\section{Objective of the study:}

- Describe the potential of problem solving of the students of Mahasarakham University

- Compare the potential of problem solving between the group of students

- Purpose the strategies to improve problem solving potential

\section{MATERIALS AND METHODS}

Research design: This study was a descriptive research design.

Population and sample: The target population were 5,953 . They were the first year students submitted by the year 2006. Cluster random sampling was employed to define the sample. The sample consisted of 355 from 3 domain group: (1) human and social science, (2) science and technology and (3) health science group.

\section{Research instruments:}

- The problem solving inventory used as the research instrument (Heppner and Peterson, 1982) which comprised of three components 35 items and 3 domains; (1) problem solving confidence (2) approach-avoidance style and (3) personal control. The problem solving inventory scale was a rating scale with 6 levels. The interpretation divided in 3 level; (1) 35.00-93.33 = good, (2) 93.34-151-67 = fair and (3)151.68-210.00 = not good. The instrument reliability, Cronbach's Alpha coefficient $=0.84$ (Total scale) .

- Indept interview and open-ended questionnaires for qualitative data.

Data collection procedure: collecting from JuneAugust, 2008 by research assistant team.

Data analysis: Descriptive statistic and inferential statistic (t-test, F-test) were applied.

\section{RESULTS}

Demographic characteristics: The majority of the subjects were female $(n=274,77.2 \%)$, the mean age of 18.66 with more than $55.8 \%$ over 19 years. To divided by 3 groups they were: (1) Human-Social science $(\mathrm{n}=246,69.3 \%)$ (2) Science and Technology $(\mathrm{n}=69,11.3 \%)$ and (3) Health Science group $(\mathrm{n}=40,19.4 \%)$.

Potential problem solving level: The potential problem solving level of the students were moderate level; mean scores was $102.95($ Max. = 105.33, Min. =94.86). The mean score that divided by 3 groups, there were; (1) Human-Social Science $=104.85$, (2) Health Science group $=94.86$ and (3) Science and Technology = 105.32, (the lower score indicate to a higher level of problem solving skill).

Most of the students who able to solve the problem were coping with the problem by did not avoiding. Particularly, they played attention to problem analysis, using emotional control and process of decision making. In contrast, the students whom unable to solve the problem, actually they deal with out emotional control. Some of them were avoidance and no confident to solve the problem.

To comparative the problem solving potential of students who differ in gender was not significant different $(\mathrm{t}=0.956, \mathrm{p}>0.05)$. However it was statistically significant different between group. It shown that the Health Science group were able to solve 
the problem better than the Humanity-Social science and science and technology groups, $(\mathrm{p}=0.000)$; anyway, it was not significantly different between the Humanity-Social science and Science and Technology groups $(\mathrm{p}=0.839)$.

The qualitative data, collected by in-depth interview, it found that some of them presented that the teaching style and quality of the lecturers were effect to them especially about creative thinking and problem solving. They also need advise how to adaptation in this new context and can over of the difficulties situations.

\section{DISCUSSION}

The results of the study presented the potential problem solving of the students were in moderate level. Some of them were lack of emotional control, avoiding and lack of self confidence to deal with problem.

We also found that the teaching style and quality of the lecturers were effect to creative thinking and problem solving skill improvement of those students, it was similar to the guideline of the National Education Technology Standards (2008) that indicated for six subject areas which the students should know and be able to do to help them learn more effectively. Its also can lead them to live productively in an increasingly digital world. Their were: (1) creativity and innovation, (2) communication and collaboration, (3) research and information fluency, (4) critical thinking, problemsolving and decision-making, (5) digital citizenship and (6) technology operations. According to Stankeviciene (2007), presented the different corrective procedures to improve the quality of the studies and one of those is the rise of the competence of teachers who work at Bachelor's study program, base on common way of theory and practice skills forming through the prism of problem solving, the activation of individual work with students, listening to the needs of the students and their communicative skills development. Newman (2008), educational school improvement must focus on talent development with all students learning to become complex thinkers, problem solvers and creative producers. It should based on their strengths, interests and abilities.

\section{CONCLUSION}

From these results, we suggested that the strategic of problem solving potential development should be develop by covering these elements:(1) to develop the strengthening of mental and insight (2) to develop the learning system and (3) to develop leadership more than that it should develop the instructors role in teaching for problem solving in additional with the supportive system from the institute. The further research we recommend to use Randomize Control (RCT) to test for these strategies.

\section{ACKNOWLEDGEMENT}

We would like to acknowledge Mahasarakham University for supporting this study and also special thanks to Faculty of Nursing, Mahasarakham University.

\section{REFERENCES}

Harris, R., 1998. Introduction to Problem Solving. http://www.virtualsalt.com/crebook3.htm

Heppner, P.P. and C.H. Peterson, 1982. The development and implications of a personal problem-solving inventory. 3rd Edn., Mahidol University, Thailand, ISBN: 9749717139, pp: 351354.

Lazarus, R.S. and S. Folkman, 1984. Stess, Appraisal and Coping. 1st Edn., Spring Publishing Company, ISBN: 0826141919, pp: 456.

National Education Technology Standards, 2008. http://www.nsdc.org/news/.\%20state

Newman, J.R., 2008. Talents are unlimited: It's time to teach thinking skills again. Gifted Child Today, 31: 34-44. DOI: $10.4219 /$ gct-2008-789

Nies, N.A. and M. Mc Even, 2001. Community Health Nursing: Promoting the Health of Population. WB Saunders, Philadelphia, pp: 322.

Rappaport, J. and E. Seidman, 2000. Hand Book of Community Psychology. 1st Edn., Kluwer Acardemic/Plenum, New York, ISBN: 0306461609, pp: 579.

Stankeviciene, J., 2007. Assessment of Teaching Quality: Survey of University Graduates. Proceeding of the European Conference on Educational Research, Sept. 19-21, University of Ghent, Ghent, pp: 1-9.

University of South Australia, (UniSA), 2009. Effective problem solving. http://www.unisa.edu.au/State

WorldNet Search, 2009. Definition of problem. http://wordnetweb.princeton.edu/perl/webwn 